\title{
ANACICLOSIS Y DOBLES ETÉREOS DEL HOMBRE EN EL ANTIGUO EGIPTO. LAS PRIMERAS APORTACIONES HISTÓRICAS A LA COMPRENSIÓN TOMISTA DE LA INMORTALIDAD
}

\author{
Gabriel Martí Andrés \\ https://orcid.org/0000-0002-3292-6604 \\ Universidad de Málaga \\ https://doi.org/10.15304/ag.40.1.6452
}

\section{Resumen}

La comprensión tomista de la inmortalidad se construye, en su extraordinaria grandeza y originalidad, sobre el descubrimiento más sublime del Angélico: el acto de ser. Sin embargo, podemos descubrir ya en los egipcios algunas aportaciones -si bien ciertamente indirectas- a dicha comprensión. En torno al Juicio de Osiris, a la estructura del ánima y su relación con el cuerpo y a las fases de la evolución post mortem se deslizan algunas intuiciones de gran relevancia al respecto de la naturaleza del alma que serán integradas en la metafísica griega, asumidas y elevadas por Tomás de Aquino y, desde su genialidad, proseguidas por la antropología trascendental.

Palabras clave: Tomás de Aquino, Antiguo Egipto, inmortalidad del alma, desdoblamiento, reanimación, regeneración, resurrección.

\section{Abstract}

The Thomistic comprehension of the immortality of the soul, in its extraordinary greatness and originality, is built upon the Angelic's most sublime discovery: the act of being. However, we can already find in the Egyptians some contributions —although indirect- to this comprehension. Regarding the nature of the soul, there are some intuitions of great

Recibido: 10/12/2019. Aceptado: 18/02/2020. 
relevance around the Osiris Trial, the structure of the soul and its relation with the body and the post mortem evolution phases. These intuitions will be assimilated into the Greek metaphysics, assumed and raised by Thomas Aquinas and, based on his genius, continued by the transcendental anthropology.

Keywords: Thomas Aquinas, Ancient Egypt, immortality of the soul, unfolding, reanimation, regeneration, resurrection.

\section{Introducción}

Como defiende Ignacio Guiu con gran acierto, "la composición de esencia y acto de ser es la condición necesaria de una demostración racional de la inmortalidad del alma"1. Y ello porque solo desde la distinción real es posible contemplar la inmortalidad en sí misma, en su naturaleza y en su ser. Pero la distinción real es un descubrimiento netamente tomista. En este sentido, hemos de esperar a Santo Tomás para encontrar una comprensión lograda, cumplida, cabal de la inmortalidad misma, que el Angélico hará girar en torno a la noción de sempiternidad ${ }^{2}$; y también para una demostración concluyente, acabada, plena, pues la incorruptibilidad del alma se sustenta en la misma distinción real, a la que, en última instancia, explícita o implícitamente, remiten todas las pruebas.

Pero el tema del alma y específicamente el de su inmortalidad han sido constantes en la historia del pensamiento, hasta el punto de que es difícil encontrar cultura, sociedad, período, corriente, escuela... que se haya sustraído a él o en el que, de un modo u otro, no haya estado presente. Y así, muchos de los elementos que integran la reflexión antropológica de Tomás de Aquino en torno a la inmortalidad fueron ya propuestos por Aristóteles y otros autores, escuelas y culturas con mucha anterioridad, con tanta anterioridad que ya en las sociedades míticas más primitivas y, por supuesto, en la techne griega y en las primeras escuelas filosóficas encontramos lucidísimas intuiciones de carácter sapiencial y, en muchos casos, indicios racionales muy bien

\footnotetext{
${ }^{1}$ I. Guiu, Sobre el alma humana, Barcelona: PPU, 1992, p. 350.

${ }^{2}$ Por supuesto, la comprensión tomista de la inmortalidad invita a una mayor profundización, anima a un ulterior esclarecimiento y se abre a una fecunda prosecución. Y así, Tomás de Aquino, con su noción de sempiternidad, pone las primeras piedras de toda una antropología trascendental, una antropología que en la modernidad ofrecerá lucidísimos desarrollos en torno a propiedades que — en cuanto trascendentales- se convierten con la sempiternidad, pero que permiten descubrirla en nuevas dimensiones: libertad como apertura trascendental, destinación radical a lo irrestricto, autotrascendencia real, crecimiento in essendo...
} 
construidos en torno a la incorruptibilidad en el ámbito de la psiqué. La comprensión tomista de la inmortalidad se construye, en muy buena medida, sobre dichas aportaciones, y no sería posible entenderla en lo que tiene de extraordinaria originalidad sin atender a sus fuentes directas e indirectas.

El mismo Santo Tomás y los grandes autores del Medievo se consideran herederos del pensamiento clásico. Así es. Juan de Salisbury atribuye a uno de los más grandes maestros de la Escuela de Chartres la siguiente frase:

Decía Bernardo de Chartres que somos como enanos a hombros de gigantes, de tal modo que podemos ver más cosas y más lejanas que ellos, no ciertamente por la agudeza de nuestra vista o la envergadura de nuestro cuerpo, sino porque somos elevados a su altura y levantados por su gigantesca magnitud ${ }^{3}$.

Pues bien, este texto, que pone de manifiesto la veneración de Bernardo y de toda la Escuela de Chartres por los grandes maestros de la antigüedad, así como su lucidísima comprensión de la continuidad y el carácter acumulativo del pensamiento y de la historia de la filosofía, es destacado con gran acierto por Gilson como expresión del espíritu de la filosofía medieval en su conjunto. Este espíritu, que para Gilson encuentra formulación cumplida en la expresión "a hombros de gigantes", es descrito por él en estos términos:

Lo que los filósofos de la Edad Media les piden [a los principios de la filosofía griega] es (...) todo y nada más que aquello por lo cual son verdaderos; donde aún no lo son completamente, cómo pueden llegar a serlo. Elaboración delicada, a veces sutil, pero en la cual San Buenaventura, Santo Tomás de Aquino y Duns Scoto dan siempre prueba de extrema firmeza. Nada artificial hay en sus métodos, pues nunca fuerzan los principios con violencia que amenace destruirlos, pero los amplían cuanto es menester para hacerles decir todo lo que pueden decir y hacerles entregar la totalidad de su verdad ${ }^{4}$.

Para los medievales, no se trata simplemente de explicitar, comentar o repetir el pensamiento clásico, ni tampoco se trata de hacer decir a los griegos lo que no quisieron decir, sino de destacar lo que se estima la verdad de sus sistemas para construir sobre ella los sistemas propios. De este modo, no se puede explicar la filosofía medieval en su extraordinaria riqueza y originalidad sin la genialidad de sus máximos representantes, pero tampoco sin atender al modo en que comprendieron, vivieron y forjaron su propia filosofía a partir de los principios del pensamiento clásico:

${ }^{3}$ J. de Salisbury, Metalogicus, III, 4 (P.L., t. CXCIX, col. 900C). "Dicebat Bernardus Carnotensis nos esse quasi nanos, gigantium humeris incidentes, ut possimus plura eis et remotiora videre, non utique proprii visus acumine, aut eminentia corporis, sed quia in altum subvehimur et extollimur magnitudine gigantea”.

${ }^{4}$ E. Gilson, El espíritu de la filosofía medieval, Madrid: Rialp, 2009, pp. 385-386. 
Creyeron que la filosofía no podía ser la obra de un hombre, cualquiera sea su genio, sino que, como la ciencia, progresa por la paciente colaboración de las generaciones que se suceden, cada una de las cuales se apoya en la precedente, para excederla ${ }^{5}$.

Estos principios sobre los que los medievales construyeron sus sistemas son, en primer lugar, los de los maestros de la Antigua Grecia -muy especialmente Platón y Aristóteles-, en los cuales nace propiamente la filosofía; pero también los de otras culturas prefilosóficas que ejercieron un notable influjo en estos y que, de ese modo, pasaron a formar parte del acervo intelectual de Grecia. En efecto, el espíritu que animó el pensamiento medieval y muy especialmente el de Tomás de Aquino se mueve con el afán de construir sobre los pilares de la filosofía griega... pero estos fueron forjados en muy buena medida con los materiales provenientes de otras culturas.

Y así, para una recta comprensión de la doctrina tomista de la inmortalidad, en lo que tiene de ampliación y profundización, pero también en lo que tiene de descubrimiento radical, hemos de retrotraernos hasta los primeros testimonios escritos de la sabiduría humana, pues aunque sociedades como la egipcia o la mesopotámica no influyeron, obviamente, de modo directo en Tomás de Aquino, sí que lo hicieron en la cultura griega, a la que los medievales, como decimos, contemplarán con veneración y ánimo de prosecución. "La deuda de la Edad Media con Grecia es inmensa" ${ }^{6}$... y la deuda de esta con las culturas más antiguas del Oriente Próximo no es menos grande. $Y$ esto hasta el punto de que ya en Egipto encontramos nociones acerca de la inmortalidad que serán integradas en la filosofía griega y sobre las que, por tanto, aunque de un modo ciertamente indirecto, también se forjan los grandes sistemas del Medievo ${ }^{7}$.

Dicho esto, dejémonos poseer por ese espíritu de la filosofía medieval, que encontramos en la médula de los grandes sistemas de la Edad Media, y estudiemos los grandes hitos históricos en la intelección de la incorruptibilidad, de la inmaterialidad, de la intemporalidad, de la inmutabilidad... en el ámbito de la naturaleza humana, a fin de constatar sus respectivas aportaciones a la sublime comprensión de la inmortalidad del alma que, en

${ }^{5}$ Ib. p. 386.

${ }^{6}$ Ib. p. 385 .

${ }^{7}$ Esta influencia es especialmente significativa en las doctrinas en torno al Juicio de ultratumba (vid. M.A. Arroyo de la Fuente, "Evolución iconográfica e iconológica del Juicio osiriaco en la Edad Media”, en Revista Digital de Iconografía Medieval, vol. IX, n 17, 2017), con coincidencias muy claras entre determinadas representaciones cristianas del Juicio final y el Juicio de Osiris, y también en ciertas representaciones en torno a la resurrección, si bien la resurrección en cuanto tal, entendida en su sentido propio y radical, es — como veremosuna novedad absoluta del dogma cristiano. 
torno al extraordinario descubrimiento del actus essendi, nos ofrece Tomás de Aquino. Y ello comenzando, como es de justicia por lo que acabamos de decir, por la concepción egipcia de la inmortalidad ${ }^{8}$.

Pero antes de estudiar los distintos elementos de dicha concepción, es importante hacer dos observaciones. En primer lugar, hemos de advertir que no se trata aquí de ofrecer un exhaustivo estudio de la antropología y la escatología egipcias, sobre las que - a pesar de no hacer Egipto un tratamiento sistemático de estas cuestiones- podemos encontrar numerosísimos tratados de los más cualificados especialistas en egiptología; se trata solo de hacer emerger — perfilando sus líneas maestras- aquellos de sus elementos doctrinales medulares que, de una u otra manera, han pasado a formar parte del acervo intelectual de Occidente y de la comprensión tomista de la inmortalidad.

Por otra parte, Egipto sufrió una profunda evolución tanto en lo que respecta a la organización política como en la configuración de sus doctrinas antropológicas y creencias religiosas a lo largo de su dilatadísima historia. El mismo panteón sufrió profundas modificaciones, desde las muy diversas configuraciones locales correspondientes a los distintos clanes predinásticos hasta la consolidación de una más o menos común y extraordinariamente compleja jerarquía "oficial" de divinidades que se fue forjando a lo largo de los tres grandes períodos del Imperio y a través de un larguísimo y tortuoso proceso de unificación del Estado. De hecho, hay egiptólogos que cuantifican en varios miles el número de dioses y semidioses que podemos encontrar en las muy diversas y numerosísimas fuentes escritas de la cultura egipcia.

En lo referente a la misma escatología, además de una paulatina generalización —democratización dirían los egiptólogos- de los caminos y privilegios de la inmortalidad, que en un principio estaban reservados a los faraones, encontramos diferencias notables entre los textos que, al respecto, han sido los más representativos en los distintos períodos del Imperio -Textos de las pirámides (Imperio Antiguo), Textos de los sarcófagos (Imperio Medio) y Libro de los muertos (Imperio Nuevo) - ${ }^{9}$. Y no solo dife-

\footnotetext{
${ }^{8}$ Egipcios y sumerios constituyen las primeras civilizaciones de la historia, con orígenes muy cercanos en el tiempo. Sin embargo, a diferencia de los pueblos mesopotámicos, en la cultura egipcia el alma y su supervivencia ocuparon el centro mismo del pensamiento y de la vida desde sus primeras manifestaciones.

${ }^{9}$ Si bien en algunos momentos y contextos muy concretos de la extensa historia de Egipto, en algunos testimonios escritos muy puntuales (v.gr. Cantos de Arpista), se llegó ciertamente a poner en cuestión la misma inmortalidad del alma, como advierte Ildefonso
} 
rencias notables, sino también claras contradicciones, contradicciones que hay que asumir y con las que hay que lidiar, por cuanto para el egipcio, al ser todos ellos textos sagrados - y por el culto a la Tradición-, no pueden ser desautorizados o sustituidos unos por otros. A menos que sea necesario en casos muy concretos, y para los fines de este trabajo, nos atendremos a las ideas y creencias que se presentan como más o menos constantes o definitivas en este vastísimo período de la historia de la humanidad, lo cual nos llevará a referirnos especialmente al Libro de los muertos (y, en concreto, a su versión "canónica”), que recoge buena parte de los símbolos, cultos y textos funerarios de las otras fuentes.

\section{Psicostasía, reanimación y regeneración}

Heródoto afirma en sus Historias que los primeros en defender la inmortalidad del alma fueron precisamente los egipcios, y vincula dicha inmortalidad a la transmigración ${ }^{10}$. A este respecto, no obstante, hay que hacer una importante precisión.

Sin duda los egipcios defendieron la inmortalidad del alma, pero no es del todo correcto atribuirles estrictamente la doctrina de la transmigración o metempsícosis — que implica el paso de un cuerpo a otro-, sino solo la reencarnación en el propio cuerpo, como tampoco, ya lo veremos, la resurrección en su sentido propio, sino solo una cierta regeneración. Lo que encontramos en Egipto es una cierta revitalización o reanimación del propio cuerpo, por un lado, y la transformación o transfiguración del alma en objeto, planta, animal o divinidad, por otro:

Quien conozca este libro en la tierra o quien lo tuviese escrito en su sarcófago podrá salir al día bajo todos los aspectos que pueda desear (tomar) y entrar (otra vez) en su morada sin ser rechazado ${ }^{11}$.

Ambas doctrinas — reanimación y transfiguración- que, no obstante, están sin duda en el origen de la metempsícosis griega, forman parte, sin embargo, de una visión más amplia del devenir de las ánimas hasta su destino final y que se ha dado en llamar anaciclosis. El ánima, tras la muerte

Rodríguez Casanova (cfr. I. Robledo Casanova, "Los misterios de los egipcios: el hombre, sus componentes y el Más Allá”, Alicante: Biblioteca Virtual Miguel de Cervantes, 2006, p. 4), se puede considerar esta, sin embargo, una doctrina constante y central en el pensamiento y en la vida egipcios.

${ }^{10}$ Cfr. Heródoto, Los nueve libros de la Historia, lb. II, 123.

${ }^{11}$ Libro de los muertos (trad. F. Lara Peinado), Madrid: Tecnos, 2018, cp. 72, p. 134. 
del hombre, ha de comparecer y dar cuenta de su vida (psicostasía o Juiciopesaje del ánima) ante el tribunal presidido por Osiris, rey de los muertos. En dicho Juicio asisten a Osiris 42 dioses, que desempeñan funciones muy diversas en el proceso; entre ellos se encuentran su hijo Horus - que presenta al justificado, ya parcialmente purificado en el Juicio, ante su padre-, Isis y Neftis - Verdad y Justicia, que flanquean el trono de Osiris-, Anubis - dios guía o psicopompo, además de testigo acreditado del proceso-, Maat — cuya pluma hace de contrapeso al ánima del finado-, Ammyt — que devora el corazón del condenado- y Thot — dios de la sabiduría y notario en el proceso- ${ }^{12}$ :

¡Loor a vosotros, dioses que tenéis asiento en la Sala de las Dos Maat [Verdad y Justicia]! Os conozco y conozco vuestros nombres. No caeré bajo vuestros cuchillos; no haced sobre mí un malévolo informe ante el dios de cuyo cortejo formáis parte (...). Decid las cosas justas que me corresponden (por mi actuación en la tierra) ante el Señor del Universo, porque yo practiqué la Justicia y la Verdad en Egipto ${ }^{13}$.

Tras esta primera declaración de inocencia por parte del finado, comienzan los sucesivos interrogatorios de un largo proceso judicial. Si a resultas de dicho Juicio el veredicto es favorable, el ánima iniciará un proceso de evolución, idas y vueltas a la tumba y sucesivas trasformaciones que, solo si lo desea - pues, como veremos, puede querer permanecer en la antesalay consigue superar todas las dificultades del camino, le acabará llevando a alcanzar la iluminación total en la ya definitiva presencia de la Corte celestial de los dioses, la "inmortalidad astral" ${ }^{14}$ bajo el Sol de $\mathrm{Ra}^{15}$. Es en este proceso en el que cabe hablar de la reanimación ("reencarnación” para algunos especialistas, pero entendida, ya decimos, como revitalización del

${ }^{12}$ La lista de los dioses no es exactamente la misma en todos los papiros conservados, pero el número de 42 y la participación de las divinidades mencionadas son una constante en su conjunto.

${ }^{13}$ Libro de los muertos, op. cit., cp. 125, pp. 219-220.

${ }^{14}$ O. Piulats Riu, Egiptosophia. Relectura del Mito al Logos, Barcelona: Kairós, 2006, p. 156.

${ }^{15} \mathrm{Ra}$ (Atón-Ra, Amón-Ra) fue el dios más venerado entre los egipcios. Rey de los dioses, padre de los faraones, razón de la vida y principio último de la verdad, la justicia y la armonía cósmica. Ra, como Primer Principio Activo, puede decidir en determinados casos, como ya veremos, la destrucción del mundo y su vuelta al origen, y ciertamente sobreviviría a dicho cataclismo por anegamiento, pero no puede ser considerado eterno, por cuanto tiene un origen temporal. En efecto, Ra emerge del seno de Nun - Primer Principio Pasivo-, principio acuoso y germen creador del conjunto de lo real, constituyéndose, eso sí, desde el momento de su nacimiento, en el mismo espíritu de dicha divinidad primigenia. Este carácter primigenio del agua lo encontraremos también en las religiones mesopotámicas, en la mitología griega y en la física de los primeros filósofos. 
propio cuerpo) y de la transfiguración (transformación en muy diversos seres de muy distinta categoría ontológica, tanto vivos como inertes) como posibles momentos:

Pero el gran dilema egipcio era cómo conciliar la ley de la existencia, la ley de las múltiples anaciclosis y/o reencarnaciones con el vivo deseo de ganar la iluminación y quedarse con los dioses en el cielo.

Este dilema además habría que matizarlo en cuanto que las almas que superaban el juicio y continuaban en el Duat su evolución y sus transformaciones y sus visitas al Campo de las Juncias, no todas podían alcanzar el estado de Imakbu, de iluminación que junto a los dioses les hacía escapar de la ley de la existencia y, por tanto, de la reencarnación.

La solución a esta aparente aporía creemos que puede resolverse si aceptamos que los egipcios conocían bien que durante la vida post mórtem la reencarnación era una posibilidad real a la que estaban sujetas las almas que no conseguían ascender hasta la barca solar y estar con los dioses en las estrellas. Sólo una minoría podía escapar a la reencarnación, y en cambio una mayoría quedaba sujeta a ésta ${ }^{16}$.

Ciertamente, la doctrina de la transmigración es difícilmente compatible con la identidad del alma - por cuanto en la metempsícosis el alma ha de conformarse a otro cuerpo- - y todavía más con su intrínseca vinculación al cuerpo propio más allá de la muerte, principios básicos en la visión egipcia de la naturaleza humana, como se aprecia en los ritos funerarios y queda patente en el Libro de los muertos. Pero, como decimos, los egipcios no defienden en sentido estricto la metempsícosis, sino la reanimación sucesiva del propio y mismo cuerpo y la transfiguración igualmente sucesiva del ánima en otras entidades. La forma de entender la reanimación en el Antiguo Egipto, ciertamente, no fue siempre la misma, sufriendo notables modificaciones y matizaciones a tenor de la evolución de la religión oficial — como ya advertimos más arriba- y a lo largo de este extensísimo período de nuestra historia. Pero la vinculación del ánima con el cuerpo propio es una constante en Egipto.

Pues bien, todo esto es lo que sigue a una sentencia favorable. Por el contrario, si el veredicto del Juicio de Osiris era desfavorable, el corazón (ib), que encarna las facultades más elevadas y propias del alma humana ${ }^{17}$,

${ }^{16}$ O. Piulats Riu, op. cit., p. 160.

17 “Órgano de la vida física era el corazón (ib), sede de la vida consciente y, por lo tanto, elemento imprescindible, donde se situaban la conciencia, la razón y los deseos” (F. Lara Peinado, Introducción a El libro de los muertos, Madrid: Tecnos, 2018, p. XXXVI). Encontramos en Egipto, pues, un claro cardiocentrismo. "En el contexto de la antigüedad había un cardiocentrismo que sostenía como sede de la vida mental el corazón, existiendo ya desde los antiguos egipcios. (...) En el antiguo Egipto, el corazón fue considerado un órgano mítico privilegiado, el sitio de la inteligencia y del alma, con olvido del cerebro al que relegaban 
era arrojado a Ammyt, que lo devoraba totalmente ${ }^{18}$. Se infiere, pues, que el ánima solo puede morir por aniquilación, devorada por un poder sobrenatural:

Hay que decir, sin embargo, que para los culpables, para los declarados enemigos de Osiris, no existía el suplicio eterno, sino algo infinitamente peor: la aniquilación total tras las torturas, la no existencia ${ }^{19}$.

Ahora bien, la potencia para dejar de ser en absoluto - en este caso, morir por aniquilación- solo puede entenderse como potencia obediencial, y esta potencia se contrapone a la natural, de tal modo que - como dice Tomás de Aquino- "nada puede decirse corruptible por esta sola potencia" ${ }^{20}$. Así, en cuanto que el ánima solo puede morir por potencia obediencial, podemos aseverar que la inmortalidad es para los egipcios una propiedad natural. Sin duda un primer paso de extraordinaria importancia en la intelección de la inmortalidad, y muy especialmente en la comprensión tomista del espíritu.

Pero, ¿qué podemos decir de la resurrección? Buena parte de los egiptólogos atribuyen a Egipto la doctrina de la reencarnación, pero esta, como hemos visto, no puede entenderse en la cultura egipcia más que en un sentido impropio: reanimación natural del propio cuerpo como una manifestación más de la inmortalidad natural del ánima. Pues bien, una parte no menor de los especialistas atribuyen a dicha cultura la doctrina de la resurrección, pero esta no puede adscribirse a ella más que entendida en un sentido igualmente equívoco: la regeneración final del hombre a una nueva vida —una vida en plenitud bajo la sempiterna Luz de $\mathrm{Ra}$ - solo en sus componentes carentes de densidad que, si bien requiere el favor de los dioses, no es más que la manifestación más elevada de la inmortalidad natural del ánima.

En efecto, la reanimación no es más que una vuelta momentánea de un ánima en tránsito a su tumba que no altera la naturaleza del cadáver —no deja de ser una momia-, que solo se vale de él como medio en su camino de salvación y que, por tanto, no constituye una vuelta a la vida del yo muerto, del sujeto corrompido, del hombre que fue el que sufrió la

a un papel secundario" (J.L., Rivera Salazar, "La controversia sobre la sede del alma en la antigüedad”, en Boletín Científico Sapiens Research, Bogotá, vol. 6 (2), 2016, pp. 21-22).

${ }^{18}$ Cabe una tercera posibilidad, muy remota, a saber, que las acciones conformes a la Verdad y la Justicia y las contrarias pesen exactamente lo mismo. En ese caso, el ánima será destinada a prestar servicio a Osiris para toda la eternidad.

${ }^{19}$ F. Lara Peinado, op. cit., p. XXXV.

${ }^{20}$ Tomás de Aquino, Summa contra gentiles, lb. 2, cp. 55, n. 14. La traducción es mía. 
descomposición como tal. La reanimación egipcia supone la construcción de una nueva unidad accidental que, en cuanto que tal, ni siquiera a la revivencia de Lázaro ${ }^{21}$ — tal como es narrada en el texto bíblico- puede compararse, pues Lázaro, habiendo nuevamente de morir, recupera, si bien temporalmente, su unidad sustancial.

Y en la glorificación sucede algo análogo. La entrada en el Reino de la Luz constituye ciertamente una regeneración, un renacimiento, una nueva vida de naturaleza ahora ya divina. Pero esta nueva vida afecta solo al ánima, no al hombre, no al yo entendido como unidad cuerpo-ánima, que es propiamente lo que murió. En este sentido, no se puede hablar estrictamente de resurrección tampoco en este caso ${ }^{22}$.

El vínculo cuerpo-ánima se ha de mantener siempre firme, mediante los rituales preceptivos, pero solo porque esta es la garantía de que las dimensiones etéreas del hombre, en las que - si bien en distinto grado- radica realmente la individualidad del yo para los egipcios, permanezcan cohesionadas en el camino hacia la Luz. Pero el cuerpo es concebido solo como un medio, como un instrumento y vehículo para la salvación que, por eso mismo, una vez alcanzada la plenitud, pierde todo valor. Ya en la Campiña de las Juncias - o de los Juncos-, el cuerpo se torna prescindible, por cuanto el sustento del ánima está garantizado, como ahora veremos, pero en el Reino de Ra se hace del todo despreciable, por cuanto el auténtico ser del individuo es el ánima y el conglomerado unitario de sus dimensiones etéreas.

La resurrección en su sentido estricto, así como la reanimación del propio cuerpo, no pueden entenderse más que como una acción sobrenatural que haga a la propia carne volver a ser lo que dejó de ser por su propia naturaleza, algo que, como vemos, en ningún caso es postulado por los egipcios. En este sentido, encontramos en el cristianismo una novedad absoluta bien desarrollada por el Angélico. Sin embargo, dicha regeneración

${ }^{21}$ En el caso de Lázaro, es más correcto hablar de revivencia que de resurrección, por cuanto esta, entendida en su sentido más hondo y radical, exige la participación plena del cuerpo en el ser del alma (inmortalidad) y, por tanto, una elevación de la naturaleza corpórea a la condición de cuerpo espiritual.

${ }^{22}$ Si estableciéramos una analogía con la religión profesada por el Santo de Aquino, dicho renacimiento, salvando las distancias, es más afín —en su sentido y alcance- al bautismo que a la resurrección: "El hombre fue privado en su origen de la vida espiritual por el pecado original (...); y aún cualesquiera pecados que se añaden le apartan de la vida. Así pues, fue necesario que el bautismo, que es generación espiritual, tuviera tal virtud que suprimiera tanto el pecado original como todos los pecados actuales cometidos" (Tomás de Aquino, op. cit., lb. 4, cp. 59, n. 1. La cursiva y la traducción son mías). 
final que postulan los egipcios tiene en su base el reconocimiento de una inmortalidad natural que, como decimos, supone el primero y uno de los principales pasos en la configuración de la pneumatología tomista.

Por lo demás, la corta vida del condenado hasta su aniquilación final está plagada de tormentos, pues su segunda y definitiva muerte en las fauces de Ammyt es agónica, pero la vida del alma justa hasta su plena glorificación tampoco es nada fácil. El cuerpo momificado requiere ajuares y continuas ofrendas por parte de los vivos (directas o talladas para su vivificación ritual en la sepultura) que ayuden al ánima del difunto a sobrellevar el arduo camino, al menos hasta alcanzar la Campiña de las Juncias, así como muy diversas fórmulas, invocaciones, sortilegios y encantamientos por parte del ánima en tránsito para superar los muy diversos obstáculos que puede encontrar en su peregrinaje (dichas fórmulas son las recogidas en textos funerarios como el Libro de los muertos, del que el cadáver debía contar con un ejemplar en su enterramiento). Las dádivas y rituales mortuorios dejan de ser necesarios una vez alcanzada la Campiña de las Juncias, pues el trabajo en estos terrenos de Osiris procurará al difunto todo lo necesario para su vida de ultratumba ${ }^{23}$ :

En la Campiña de las Juncias estos disponen de una amplia libertad de movimientos y llevan una existencia gozosa, libres de las inquietudes que habían tenido en su vida terrena, pero de algún modo se piensa que la vida plena del espíritu no se desarrollará en este lugar, sino en otro mundo más elevado una vez que ultimado el proceso de Glorificación el ba consiga salir a lo que los egipcios denominaban Plena Luz del Día ${ }^{24}$.

La Campiña de las Juncias es, de este modo, el estadio supremo dentro del Duat o Amenet, morada inframundana de los muertos gobernada por Osiris $^{25}$, pero no el destino final de las ánimas. En ella el ánima ve colmadas

${ }^{23}$ No obstante, es difícil determinar para los vivos cuándo un ánima ha alcanzado la Campiña o la glorificación —ni siquiera en el caso de los faraones, aunque en este caso, no obstante, se tenga la certeza de que la divinización acontecerá tarde o temprano-, con lo que, para los egipcios, el culto al cadáver ha de mantenerse siempre. En este sentido, la protección de la tumba frente a los intentos de profanación o saqueo es de vital importancia; sin embargo, a medida que el ánima va ascendiendo a regiones superiores del inframundo, los posibles actos de violencia sobre el cadáver afectarán en menor grado al auténtico ser del individuo, por cuanto los frutos cosechados en los Campos de Osiris harán posible una existencia cada vez más independiente del cuerpo.

${ }^{24}$ I. Robledo Casanova, art. cit., p. 15.

${ }^{25}$ Los egipcios hacían corresponder el periplo de las ánimas separadas con el recorrido de la barca solar de $\mathrm{Ra}$ - a la que se subirán una vez alcanzada la glorificación-, y por ello sitúan el Duat en la oscuridad del cielo inframundano, por el que han de transitar dichas ánimas hacia el pleno amanecer en un Reino triunfante de Luz. 
todas sus necesidades de subsistencia y alcanza la feliz serenidad en sus afectos y una total libertad de movimiento, pero la plenitud, la inmortalidad astral, la divinización en la reunión de todos sus componentes y dinamismos solo es alcanzada en el Reino de Ra, bajo la iluminación total en la eterna presencia de la Corte celestial de los dioses.

\section{Los dobles etéreos del hombre: ka, ba y aj}

Como se desprende de lo que acabamos de decir, los egipcios no conciben al ánima como un principio único —algo imprescindible para poder hablar de forma sustancial-. Y así, se refieren a la dimensión etérea (la espiritualidad no está aún debidamente conceptualizada) del hombre con muy diversas denominaciones. Cada una de ellas expresa uno de sus múltiples modos, que conviven y que acompañan al cuerpo antes y/o después de la muerte. Y así, junto al jat (djet), que es el cuerpo físico en su estado natural - vivo o muerto sin embalsamar-y, por tanto, expuesto a la corrupción (sin las fuentes de energía sería mero cuerpo inanimado ${ }^{26}$ ) y el sah - garante de la pervivencia del individuo en el Duat-, que es el cuerpo muerto elevado y preservado de la descomposición mediante los preceptivos rituales funerarios ${ }^{27}$, destacan, como elementos más o menos "esenciales", el ka, el ba y el aj (akh).

El $k a$ es una cierta especie de hálito o aura que, con su fuerza generatriz, vital y afectiva de naturaleza psíquica y participada del cosmos, da energía y protege al cuerpo físico, a su sombra y —en distinta medida y de distinta forma- al alma en general antes y después de la muerte, requiriendo en el Duat - no obstante - ofrendas, cuidados y alimentos con alcance anímico para conservar su naturaleza e intensificar su poder:

Que le sea flanqueado el camino a mi alma, que mi sombra pueda ver al Gran dios en el interior de la capilla el día en que se juzgan las almas y que ella pueda repetir mis palabras a Osiris. Los de las moradas ocultas, los guardianes de los miembros de Osiris, los que guardan a los bienaventurados, los que tienen encerradas las sombras

${ }^{26}$ Estado en el que, como sugerimos, quedará el cuerpo tras la glorificación del ánima. En efecto, el auténtico ser del hombre es el ánima y, una vez alcanzado por esta el estado de Imakhu, el cuerpo pierde toda vinculación con ella y, por ende, toda participación en la vida del individuo.

${ }^{27}$ Dichos rituales y liturgias giraban en torno al embalsamamiento o momificación, cuyas técnicas evolucionaron con el paso de los siglos y eran diversas en función del estatus social del finado, pero que siempre fue concebido como algo crucial para la conservación de la integridad individual del difunto. 
de los muertos (y) que podrían hacerme mal ¡que no me hagan ningún daño! ¡Ve, alma mía, que estás alejada, a tu $k a$ (para que) esté contigo! ${ }^{28}$.

"El ka sería una especie de doble energético del hombre, que se situaría en un espacio intermedio entre el cuerpo y el propio espíritu" ${ }^{29}$. En el Libro de los muertos podemos leer la siguiente fórmula dirigida al propio corazón en el momento del pesaje:

Tú eres mi ka que habitas en mi cuerpo, (eres) el Khnum que das forma y vida a mis miembros. ¡Ve hacia la felicidad que nos está preparada allí! ${ }^{30}$.

Resulta muy significativa la correspondencia que se establece entre el $k a$ y Khnum, que es una divinidad que se encuentra triplemente en el mismo principio de la vida: es uno de los dioses creadores, en concreto de la vida y muy especialmente de la vida humana; está vinculado con el mismo Ra (Khnum-Ra), principio absoluto de todo lo creado; y es el dios de las aguas diferenciadas, procedentes originariamente del principio acuoso y germen creador del conjunto de lo real (Nun).

El $k a$ es la energía con la que cada individuo participa de la energía universal y, por tanto, la fuerza primordial que reside en cada ser humano; es el principium vitae de cada persona, un principio sagrado procedente del mismo manantial de la vida y, por tanto, lo cósmico-divino que habita nativamente en cada individuo y cuya concurrencia es fundamento para la divinización de la naturaleza misma del ánima glorificada ${ }^{31}$. Pero, ¿acaso el alma en la comprensión tomista — como ya en la filosofía griega, patrística y altomedieval- no es principio de vida? ${ }^{32}$ Aunque la disgregación del ánima y del mismo $k a$ hace impropio hablar de alma en sentido estricto, encontramos aquí un nuevo elemento que puede ser y, de hecho, fue perfectamente integrado y asimilado por la antropología tomista.

${ }^{28}$ Libro de los muertos, op. cit., cp. 92, p. 163.

${ }^{29}$ I. Robledo Casanova, art. cit., p. 8.

${ }^{30}$ Libro de los muertos, op. cit., cp. 30b, p. 84.

${ }^{31} \mathrm{El} \mathrm{ka}$ no es el único principio divino con el que cuenta nativamente el ánima, como ahora veremos, pues también goza de una semilla del mismo Ra, pero sí es el único principio supraindividual en cuanto participación del cosmos — de la energía cósmico-divina- en su conjunto. Su importancia para la salvación es, en este sentido, vital, pero - como veremosno podríamos hablar de la inmortalidad de un alma individual ni de la divinización de la naturaleza misma del ánima en su individualidad si el complejo anímico se redujera a él.

${ }^{32}$ Cfr. Tomás de Aquino, op. cit., lb. 3, cp. 139, n. 17. "Mortale autem est quod animam spirituali vita privat. Cuius quidem vitae ratio ex duobus sumi potest, secundum similitudinem vitae naturalis. Vivit enim corpus naturaliter per hoc quod animae unitur, quae est ei principium vitae". La cursiva es mía. 
Por otra parte, también los dioses gozaban de uno o varios $k a$. Y ello empezando por el mismo Ra, en el que, en su unión con Khnum, se cuentan en número de catorce (subsistencia, alimentación, valentía, fuerza, iluminación... $)^{33}$.

Por lo demás, "los egipcios creían que las personas que alcanzaban un adecuado conocimiento podían llegar a actuar en constante y consciente armonía con la energía de su ka, lo que suponía una primera superación de las limitaciones que para el hombre implica su propio cuerpo o envoltura física" ${ }^{34}$. Una superación que se da en vida. Esto implica, claro está, actuar de acuerdo con el bien de la propia naturaleza benefactora de Maat, principio de la Verdad y la Justicia, algo sobre lo que el corazón será pesado en el Juicio de Osiris.

El $k a$ permanece tras la muerte, y no deja de mantener una cierta vinculación con su cuerpo y el de sus antepasados y descendientes. Sin embargo, en la religiosidad egipcia la individualidad del $k a$ quedaba seriamente comprometida, en muy buena medida por ser energía participada de la fuerza vital cósmica, con lo que, en principio, no cabría ver aquí antecedente alguno a la comprensión tomista del alma — más bien al neoplatonismo- si no fuera porque el ánima, para los egipcios, no se reduce al $k a$ y porque el mismo $k a$ es alcanzado de algún modo por la individualidad de las otras formas anímicas, como iremos viendo en el estudio de las mismas.

El $b a$ acompaña al cuerpo en la vida terrenal, y es en él en el que propiamente sobrevive la identidad del individuo después de la muerte. Es especialmente activo tras la muerte, en conexión con el sah o cadáver ritualizado, y, salvando las enormes distancias, es en el mundo egipcio lo más cercano a lo que en la filosofía occidental se designa con el término alma:

He aparecido como un halcón divino, (porque) Horus me ha dotado de su ba para llevar sus pensamientos a Osiris y a la Duat.... Horus me había dotado de su ba y vi lo que había allí dentro; (pero), si (lo) digo, los poderosos de Shu me expulsarán y quebrantarán mi arrogancia. Soy el que ha sido encargado de traer sus pensamientos a Osiris y a la Duat. Soy yo, halcón que habita en la luz, el que es poderoso gracias a su diadema, el que es poderoso gracias a su resplandor (y) realizaré la ida y el regreso hasta los confines del cielo ${ }^{35}$.

El $b a$ es el principio en el que recae propiamente la inmortalidad, la inmortalidad individual, y aquel elemento que capitanea el tortuoso camino del ánima por el Duat — y sus doce regiones— hacia la Luz de Ra, hacia la

\footnotetext{
${ }^{33}$ Cfr. Libro de los muertos, op. cit., cp. 15, p. 29.

${ }^{34}$ I. Robledo Casanova, art. cit., p. 9.

${ }^{35}$ Libro de los muertos, op. cit., cp. 78, pp. 141-142.
} 
felicidad y libertad eternas, una vez superado el Juicio de Osiris. Es el $b a$ el que habrá de seguir las fórmulas contenidas en el Libro de los muertos para superar los obstáculos que a buen seguro encontrará en su camino de salvación.

Por ello, las prácticas iniciáticas son especialmente importantes para el ba. Es importante experimentar en vida nuestra propia "espiritualidad" vivencia que es muy limitada en el $\mathrm{ka}$-, activar nuestra capacidad de trascender lo puramente material y de movernos libremente por el reino de lo eterno, tomar conciencia antes de morir de nuestro propio $b a$. Se trata, en definitiva, de adelantar ficticiamente, mediante rituales iniciáticos, nuestra propia muerte a fin de ensayar nuestro vivir de ultratumba y las fórmulas mágicas que habremos de emplear para superar los peligros, miedos, trampas y obstáculos con el que el ba se encontrará después de la muerte en su camino por el Duat. Este aprendizaje solo se puede adquirir, por tanto, mediante una cierta forma de éxtasis místico: "Se trataría de que el iniciado pudiese vivir la experiencia de salir de su propio cuerpo y convertido en espíritu tomar contacto con otros mundos que resultan ajenos a los sentidos humanos habituales" 36 .

No obstante, el riesgo de la aniquilación total seguirá existiendo para toda la eternidad:

Estás destinado (a vivir) millones de millones de años, (a tener) una duración de Vida (eterna) de millones de años. En cuanto a mí, yo destruiré todo lo que he creado, el país volverá al estado de Nun, al estado de Ola, como (fue) su estado primigenio. Yo soy lo que restará (de todo lo creado) junto con Osiris, cuando me transforme otra vez en serpiente, (hechos) que los hombres no podrán conocer ni los dioses podrán contemplar ${ }^{37}$.

De nuevo la potencia obediencial, en este caso ante la inundación que puede ser provocada por el Primer Principio Activo - Ra- ante una situación de desorden físico-moral universal ${ }^{38}$. Dicha potencia obediencial, que podría igualmente aniquilar al alma en vida eterna, no hace menos natural - como ya dijimos al respecto de la voracidad de Ammyt - la inmortalidad del ba: "Al ser creados por una entidad espiritual, [los egipcios] intuyeron lógicamente que en su propia esencia existían diversas potencias espirituales,

${ }^{36}$ I. Robledo Casanova, art. cit., p. 13.

${ }^{37}$ Libro de los muertos, op. cit., cp. 175 a, p. 390.

${ }^{38}$ Es imposible no reconocer en este punto ciertas similitudes con el pasaje bíblico del diluvio universal —así como con algunas representaciones griegas acerca del fin del mundo-, pero el alcance teológico de dicho relato y sus singularidades con respecto a la concepción egipcia excede con creces los límites de este trabajo. 
que no podrían desaparecer jamás, como no podían desaparecer los dioses" 39 .

Por último, también los dioses gozan de su propio $b a$, que, a diferencia de otros principios etéreos, es claramente uno y único en cada individuo, como queda patente en uno de los fragmentos que acabamos de reproducir: "Horus me había dotado de su ba y vi lo que había allí dentro..." ${ }^{40}$. La individualidad del alma aparece aquí por primera vez de forma nítida y, si bien no puede reducirse a ella la extraordinaria comprensión metafísica del alma como forma espiritual, encontramos en este punto otro antecedente muy significativo de la síntesis tomista.

El aj es, sin duda, el componente más complejo y, al mismo tiempo, más sublime del entramado anímico que da vida al individuo. Sus apariciones en el Libro de los muertos — al igual que sucede con el ba- son muy escasas en comparación con las numerosísimas referencias al $k a$, pero son suficientes para constatar su extraordinaria relevancia:

(Como) alguien que es un espíritu $a k h$, alguien que puede abrir el Occidente, (así es) tu alma excelsa, (Osiris) N., (pues) eres como uno que puede hablar, uno que es agradable al corazón de Re y querido a la asamblea de Sematyuat; eres uno a quien protegen los hombres y a quien Ruty le guía donde él da descanso a su $k a^{41}$.

Se trata de una semilla del mismo Ra - Dios supremo, Principio fontal de todo lo existente- con la que cuenta cada persona a lo largo de toda su existencia, tanto terrenal como ultraterrenal, pero que solo resplandece como haz de luz una vez que el $b a$ alcanza la plena glorificación tras su tortuoso peregrinaje por los campos de Osiris. Siempre en conexión con el $s a b$ - cadáver ritualizado- asciende con el $b a$ —en su viaje por el Duathasta alcanzar su plenitud en la presencia de los dioses y resplandecer para siempre con la eterna Luz de Ra:

Cuando el Ka se integra con el Ba, la identidad de cada ser, se produce la metamorfosis en cuerpo de Luz que es el vehículo natural del alma, el $\mathrm{Aj}^{42}$.

El aj es el modo más elevado y sutil del hombre y, como vislumbra Piulats Riu, da cierta unidad a todo el conglomerado humano, integrando a su manera, en forma de luz, todos los modos anímicos del hombre:

${ }^{39}$ F. Lara Peinado, op. cit., p. XXXVI.

${ }^{40}$ Libro de los muertos, op. cit., cp. 78, p. 142.

${ }^{41}$ Ib., cp. 169 a, p. 364.

${ }^{42}$ F. Schwarz, Egipto invisible. El poder de los símbolos, Buenos Aires: Kier, 2007, p. 114. 
La llegada del 'aj' al Cielo solar implica una equiparación, una reunión de cualidades; lo que apunta a un trabajo evolutivo personal y a una reunificación de potencialidades dispersas ${ }^{43}$.

En efecto, el destino último de las almas, como vimos, no es el Duat —ni siquiera su Campiña de las Juncias—, no es el Reino de Osiris — que constituye solo un estadio intermedio-, sino el Reino del Dios Supremo, el Campo de Ra, el Reino de la Luz. El hombre comienza con su nacimiento el camino hacia la bienaventuranza eterna, un camino que solo puede llegar a feliz término tras una vida terrenal de verdad y justicia, acorde con Maat, y un sinuoso, complejo y dificultoso periplo ultraterrenal por los dominios de Osiris.

Superadas con éxito estas dos fases de la existencia humana, el ánima accederá al mismo Reino de la Luz pura de Ra, donde será acogida por la Fuente Suprema de todo lo existente y disfrutará de felicidad eterna... "debido a la grandeza de su cualidad de espíritu aj":

El halcón ha chillado para ti, el ganso ha graznado para ti. Re te ha abierto las puertas del cielo, Geb te ha abierto la tierra, debido a la grandeza de tu cualidad de espíritu $a k h$, debido a tus excelencias, (Osiris N.), de quien se conoce el nombre ${ }^{44}$.

En el Reino de la Luz, aquellos principios anímicos que habían transitado por el Duat —especialmente el ka y el $b a$ - serán unificados, elevados y transformados en sujeto de luz, en el sujeto de una luz fulgurante y eterna - el aj-que, en cuanto participación del mismo Dios Supremo, constituye la integración absoluta de toda el ánima en la misma divinidad de Ra, "Señor del Occidente”, Dios supremo del Occidente eterno. Supone, por tanto, la divinización del "espíritu":

A través de la experiencia del akh [aj], en la iniciación en los Misterios o tras la muerte, el espíritu del hombre, transformado en Luz plena, llegaba a integrarse con $\mathrm{Ra}$, con la divinidad creadora de la que todo había surgido. El hombre, convertido en akh [aj], se integraba con dios y se hacía dios. Ese es el motivo de que el akh [aj] se entienda como el espíritu del hombre que una vez culminado el proceso de Glorificación se ha transformado en divinidad ${ }^{45}$.

${ }^{43}$ O. Piulats Riu, op. cit., p. 156. Los egipcios hablan también de otros elementos anímicos como el Ren o Nombre, de gran importancia en la cultura egipcia por expresar la singularidad, el proyecto personal y el destino del individuo, y el Shuyt o Sombra, que es el reflejo etéreo del cuerpo, que le acompaña en vida y que resulta glorificado conjuntamente con el alma (cfr. Libro de los muertos, op. cit., cp. 188, p. 415), el "doble inmaterial de cada una de las formas que el individuo habrá de tomar a lo largo de su vida” (N. Grimal, Historia del Antiguo Egipto, Madrid: Akal, p. 117).

${ }^{44}$ Libro de los muertos, op. cit., cp. 169a, p. 364.

${ }^{45}$ I. Robledo Casanova, art. cit., p. 26. 
Esta divinización, al igual que dijimos con respecto al ba y su discurrir por el Duat, puede ser fingida en vida mediante rituales mistéricos - y en este caso también en el periplo post mortem-, a fin de tomar conciencia de nuestro origen, de nuestra naturaleza y de nuestro destino, experimentando de forma adelantada la integración de todo nuestro auténtico yo en la misma Luz divina.

La divinización del ánima no compromete la individualidad, autonomía e identidad del alma glorificada. Es más, la eclosión del aj en el Reino de la Luz supone la asunción del $k a$ por parte de la individualidad del $b a$ y la elevación de todo el conglomerado anímico desde el aj. Y esta es propiamente la "resurrección" definitiva. La importancia que los egipcios daban a la identidad del ser humano, antes y después de la muerte, queda patente en la elevación del nombre propio (ren) a la categoría de componente de índole “espiritual” del individuo.

Antes de extraer conclusiones, estimo pertinente una reflexión final. Los elementos anímicos del hombre, y muy especialmente el $b a$, fueron habitualmente representados en forma de ave. Esto fue algo más o menos constante en la iconografía de cada una de las fases del Imperio ${ }^{46}$, lo cual es especialmente significativo por la vinculación ancestral entre las aves, por un lado, y la movilidad, la libertad y la eternidad, por el otro; de hecho, los faraones ascendían a la Eternidad en forma de halcón, dejando atrás el mundo terrenal con el libre agitar de sus alas. El trascendimiento, que ya empezó a traslucirse en el $k a$, si bien reducido a la trascendencia del alma sobre el cuerpo, alcanza en este punto una expresión extraordinariamente elevada en cuanto apertura a lo irrestricto, a la infinitud de una luz eterna, a una verdad inagotable, algo que, sin duda, pasando por toda la patrística y muy especialmente por Agustín de Hipona ${ }^{47}$ e Isidoro de Sevilla ${ }^{48}$, consti-

${ }^{46}$ Cfr. M.A. Arroyo de la Fuente, art. cit., p. 85.

${ }^{47}$ Cfr. Agustín de Hipona, De vera religione, 39, 72. "Noli foras ire, in teipsum redi; in interiore homine habitat veritas; et si tuam naturam mutabilem inveneris, transcende et teipsum. Sed memento cum te transcendis, ratiocinantem animam te transcendere. Illuc ergo tende, unde ipsum lumen rationis accenditur. Quo enim pervenit omnis bonus ratiocinator, nisi ad veritatem? cum ad seipsam veritas non utique ratiocinando perveniat, sed quod ratiocinantes appetunt, ipsa sit. Vide ibi convenientiam qua superior esse non possit, et ipse conveni cum ea".

${ }^{48}$ Cfr. Isidoro de Sevilla, Sententiarum libri tres, I, II, 3. "Immensitas divinae magnitudinis ita est, ut intelligamus cum intra omnia, sed non inclusum; extra omnia, sed non exclusum. Et ideo interiorem, ut omnia contineat; ideo exteriorem, ut incircumscripta magnitudinis suae immensitate omnia concludat. Per id ergo, quod exterior est, ostenditur ese creator; per id vero quod interior, gubernare omnia demonstratur. Ac ne ea quae creata sunt 
tuirá uno de los puntos medulares de la comprensión tomista de la inmortalidad y una de sus más relevantes vías de prosecución.

\section{Conclusiones}

Es cierto que existe una vinculación especial entre el jat y el $k a$, por un lado, y entre el sab y el $b a$, por otro, y una unificación de todos los componentes etéreos del hombre en el aj. Sin embargo, en el Antiguo Egipto no encontramos aún un concepto claro de espiritualidad, siendo el alma igualmente materia —aunque sutil—; ni tampoco de hombre como sustancia, como unidad de forma sustancial —en cuanto tal, única- y materia. No podemos, por tanto, hablar de alma en sentido propio, solo en el sentido impropio que le hemos dado al término hasta ahora, por contraposición a los elementos más densos — menos sutiles- del hombre, en definitiva, a los modos del cuerpo —al jat y al sab- ${ }^{49}$.

Y así:

Debemos confesar -dice Jorge Roberto Ogdon- con franqueza la incapacidad académica de precisar nítidamente la naturaleza y los atributos de las varias 'formas' que constituyen al Ser Humano de acuerdo a su cosmovisión. En el marco descriptivo y especulativo de las aproximaciones egiptológicas, todas ellas parecen 'componentes' intercambiables o similares, cuando no idénticos a la esencia humana, y la frecuente asimilación, identificación y/o interacción, en los textos antiguos, ya sea entre sí o con otros elementos más de la 'antropología religiosa' (...) complica aún más la cuestión desde un punto de vista 'occidental y moderno' ${ }^{50}$.

En este sentido, más preciso sería hablar de un desdoblamiento de la persona, de una serie de dobles que conviven, que asumen la identidad en sus ámbitos propios y que desempeñan sus respectivas funciones de una $\mathrm{u}$ otra manera en los distintos momentos del proceso evolutivo. En esta línea se mueven buena parte de los egiptólogos y antropólogos culturales, que suelen describir, muy especialmente al ka, pero también al ba y al $a j$, como distintas formas de doble o alter ego: el ka es "doble vital", "doble celeste", "segundo ejemplar del cuerpo", "doble psicoenergético", "imagen” o "doble etéreo"; el $b a$ es "doble del individuo", con el que el hombre —-defiende Robledo Casanova - toma contacto cuando se independiza del cuerpo en

sine Deo essent, Deus intra omnia est. Verum ne extra Deum essent, Deus exterior est, ut omnia concludantur ab eo".

${ }^{49}$ Por eso hemos optado por hablar de ánima más que de alma.

${ }^{50}$ J.R. Ogdon, "La naturaleza humana antes y después de la muerte según las concepciones egipcias”, en Venezuela Egiptológica, Caracas, 2015, p. 15. 
sueños u otras circunstancias ${ }^{51}$; y el $a j$ es "fantasma" o "espíritu divinizado". Los componentes anímicos del hombre son —afirma Lara Peinado"entes dotados de verdadera vida propia" ${ }^{2}$.

$\mathrm{Y}$ es que, cuando nos movemos en contextos pre o parafilosóficos - $\mathrm{y}$ también en algunas corrientes filosóficas, especialmente orientales- en los que la unidad sustancial del hombre no está conceptualizada, en lugar de alma encontramos dobles. Los hallamos claramente en la mitología griega, y también en la Edad Media, en determinadas creencias muy comunes, pero construidas al margen del pensamiento filosófico ${ }^{53}$. No descubrimos, por tanto, en este punto una contribución absoluta del Antiguo Egipto a la comprensión tomista del alma. Pero sí que podemos hablar de una aportación relativa de gran valor, pues los egipcios, como hemos visto, defienden nítidamente la identidad del alma —en los distintos modos que esta adopta- y su íntima vinculación con el cuerpo propio antes y después de la muerte - aunque sin llegar a constituir, por lo que hemos expuesto, unidad sustancial-.

Pero aún hay más. Es cierto que los egipcios carecen de un concepto metafísicamente cabal de "alma", pues no alcanzan a vislumbrar la naturaleza de la formalidad sustancial y, por tanto — como hemos visto-, la unidad radical del hombre. Sin embargo, sí que encontramos entre ropajes e imágenes de carácter mítico una intuición de gran peso en la construcción de la antropología clásica más estrictamente metafísica, pues hacen recaer el auténtico ser del individuo en el ánima, otorgándole una clara superioridad sobre el cuerpo - manifiesta sobre todo en el aj-; y, efectivamente, la forma es principio del ser del ente y, cuando esa forma es espiritual, goza en propiedad de dicho ser, siendo esto justamente lo que explica la inmortalidad del alma. Y aún podríamos decir más en este sentido. La fragmentación del ánima en $k a, b a$ y aj hace aún más difícil atribuir a Egipto un concepto metafísicamente cabal de "alma”, pero el ánima, y especialmente el $k a$, es concebido en la antropogonía egipcia claramente como principio de vida, y, efectivamente, como dice Tomás de Aquino, la forma es principio del ser y "vivir es el ser de los vivientes" ${ }^{54}$.

${ }^{51}$ Cfr. I. Robledo Casanova, art. cit., p. 12.

${ }^{52}$ F. Lara Peinado, op. cit., p. XXXVII.

${ }^{53}$ Vid. C. Lecouteux, Hadas, brujas y hombres lobo en la Edad Media. Historia del Doble, Palma de Mallorca: José J. de Olañeta, 1999.

${ }_{54}$ Tomás de Aquino, In I Sententiarum, ds. 17, qu. 1, ar. 1, ra. 2. La traducción es mía. "anima comparatur ad corpus non tantum ut causa agens, secundum quod est motrix corporis, sed etiam ut forma; unde formaliter seipsa facit vivere corpus, secundum quod vivere dicitur esse viventium". 
Por otra parte, como hemos expuesto a lo largo de este trabajo, Egipto conceptualiza claramente la inmortalidad como propiedad natural, como un predicado esencial que recae especialmente en el $b a$ y que solo puede desaparecer por aniquilación, por la aniquilación obrada desde un poder sobrenatural —el poder de Ammyt, en el caso de condena en el Juicio de Osiris, o el poder de Ra, en el caso de que el estado de depravación del mundo exigiera su destrucción por anegamiento y vuelta al origen-. Esto es, quizá, lo más relevante de la antropología egipcia y, más en concreto, de su intelección de la inmortalidad, por cuanto estará en la base de toda la especulación filosófica en torno al alma hasta nuestros días. En esta misma línea, la inmortalidad es propiedad del alma individual, de un alma que no obstante- no es unitaria, pero que no se subsume en un abismo caótico en el momento de la divinización, sino que conserva su identidad individual para toda la eternidad o hasta su posible aniquilación. La individualidad del ánima, por lo demás, es especialmente manifiesta en el ren (nombre), componente etéreo que — como vimos - goza de una extraordinaria relevancia en el pensamiento egipcio:

¿Que mi nombre (ren) me sea devuelto en la Gran Casa, que mi nombre me sea recordado en la Casa del Fuego durante la noche en la que se cuentan los años y en la que se calculan los meses! ¡Soy Imi-pui y tengo mi residencia en el lado oriental del cielo!

¡Proclamaré a mi descendencia el nombre de todos los dioses que no vengan en mi comitiva! $!^{55}$.

Pero no son estos los únicos aportes de Egipto a la comprensión tomista. Junto a otros aspectos menores como el cardiocentrismo y la relevancia de la luz como dimensión antropológica y divina, encontramos nada menos que la libertad, la inmortalidad como libertad, como libertad para trascender los límites de la materia densa del cuerpo, para atravesar el Cielo de la eternidad en busca de la Gloria, para purificar el alma de las mentiras y las injusticias, para reanimar la carne hasta la plena divinización.

Ciertamente, los egipcios devalúan la libertad, reduciéndola a liberación: el camino de la libertad —el trascendimiento activo- hacia la eterna glorificación, estando construido - como vimos- sobre una cierta apertura a lo irrestricto, es un camino de liberación, liberación de un cuerpo que no conciben como principio constitutivo sustancial del hombre, sino como un mero medio, instrumento o vehículo. Pero en ello, revestido claramente de un halo mítico, de un materialismo absoluto y de un naturalismo

${ }^{55}$ Libro de los muertos, op. cit., cp. 25, p. 77. 
antropológicamente insostenible, encontramos —no obstante- intuiciones de extraordinaria profundidad que abrirán las puertas a una comprensión filosófica cabal de la inmortalidad como libertad radical-como libertas in essendo- y que encontrará en Tomás de Aquino una logradísima expresión que dará pie a lucidísimos desarrollos modernos y contemporáneos.

Por último, aunque la colección más representativa de textos egipcios de ultratumba se ha consagrado en la modernidad con el título de "Libro de los muertos", sin embargo, el título original con el que fue reconocido por los mismos egipcios fue "Libro de la salida a la luz del día". De hecho, las primeras palabras que pueden leerse en la obra son las siguientes:

Comienzo de las fórmulas para 'salir al día' y de las transfiguraciones y glorificaciones (del bienaventurado) en el Más Allás ${ }^{56}$.

Por otra parte, como observa Ildefonso Robledo, los lugares en los que se impartían las enseñanzas mistéricas y se producían los ejemplares del Libro de los muertos eran llamados "Casas de la vida" ${ }^{7}$. Estos dos datos son especialmente significativos, pues ponen de manifiesto que la religión egipcia es religión de vida, y no de muerte, de eternidad, y no de finitud, y esto estará en la base del mismo espíritu del cristianismo, de la antropología metafísica griega y de la comprensión tomista de la inmortalidad ${ }^{58}$.

\section{Bibliografía}

Agustín de Hipona, De vera religione, Madrid: BAC, 1985.

Arroyo de la Fuente, M. A., "Evolución iconográfica e iconológica del Juicio osiriaco en la Edad Media", en Revista Digital de Iconografía Medieval, vol. IX, n 17, 2017.

Gilson, E., El espíritu de la filosofía medieval, Madrid: Rialp, 2009.

Grimal, N., Historia del Antiguo Egipto, Madrid: Akal, 2011.

Guiu, I., Sobre el alma humana, Barcelona: PPU, 1992.

Heródoto, Los nueve libros de la Historia, Madrid: Dykinson, 2011. Isidoro de Sevilla, Sententiarum libri tres, Turnhout: Brepols, 1998.

${ }^{56} \mathrm{Ib} .$, cp. 1a, p. 3.

${ }^{57}$ Cfr. I. Robledo Casanova, art. cit., p. 4.

${ }^{58}$ Para terminar, es de justicia insistir en que la influencia de Egipto en la antropología tomista no habría sido posible sin la mediación de otras culturas prefilosóficas, de la techne griega y, muy especialmente, de los grandes maestros de la Antigüedad, Platón y Aristóteles, cuyas aportaciones al respecto serán objeto de sucesivos estudios. 
Lara Peinado, F., Introducción a El libro de los muertos, Madrid: Tecnos, 2018.

Lecouteux, C., Hadas, brujas y hombres lobo en la Edad Media. Historia del Doble, Palma de Mallorca: José J. de Olañeta, 1999.

Libro de los muertos (trad. F. Lara Peinado), Madrid: Tecnos, 2018.

Ogdon, J. R., "La naturaleza humana antes y después de la muerte según las concepciones egipcias”, en Venezuela Egiptológica, Caracas, 2015, pp. 8-27.

Piulats Riu, O., Egiptosophia. Relectura del Mito al Logos, Barcelona: Kairós, 2006.

Rivera Salazar, J. L., "La controversia sobre la sede del alma en la antigüedad", en Boletín Científico Sapiens Research, Bogotá, Vol. 6 (2), 2016.

Robledo Casanova, I., "Los misterios de los egipcios: el hombre, sus componentes y el Más Allá”, Alicante: Biblioteca Virtual Miguel de Cervantes, 2006.

Salisbury, J. de, Metalogicus, en Patrología Latina. Opera Omnia, Migne, J. P., accurante, Bruselas: Typographi Brepols Editores Pontificil, 1996.

Schwarz, F., Egipto invisible. El poder de los simbolos, Buenos Aires: Kier, 2007.

Tomás de Aquino, In I Sententiarum, en Opera omnia iussu impensaque Leonis XIII edita.../ cum comentariis Thomae de Vio Caietani, Roma: Typ, Polyglotta S. C. de Propaganda Fide, 1882.

Tomás de Aquino, Summa contra gentiles, en Opera omnia iussu impensaque Leonis XIII edita.../ cum comentariis Thomae de Vio Caietani, Roma: Typ, Polyglotta S. C. de Propaganda Fide, 1882. 